УДК 378.147

\title{
ПРОБЛЕМА КОНТРОЛЮ У НАВЧАННІ ПЕРЕКЛАДУ: АНАЛІТИЧНИЙ ОГЛЯД ПІДХОДІВ ДО ПРОФЕСІЙНОЇ ПІДГОТОВКИ ПЕРЕКЛАДАЧІВ
}

\author{
Фабрична Я. Г. \\ yanafabrichnaya@gmail.com \\ https://orcid.org/0000-0003-1009-6598 \\ Київський наиіональний лінгвістичний університет \\ Дата надходження 03.11.2020. Рекомендовано до друку 04.12.2020.
}

\begin{abstract}
Анотація. Досліджуючи історію професійної підготовки перекладачів у закладах вищої освіти, авторка статті аналізує наявні підходи до навчання перекладу з метою виокремлення кола питань, релевантних аспекту реалізації контролю як складової системи відповідного навчання, з метою визначення теоретичних і практичних проблем, що потребують наукового вирішення з урахуванням специфіки теоретичного обгрунтування і розроблення методичної системи контролю у навчанні майбутніх філологів письмового перекладу в галузі освіти. Стаття висвітлює основні стратегії та методи навчання перекладу та пропонує аналітичний огляд цілей, видів і форм контролю в межах директивного, комунікативно-функціонального, професійно орієнтованого, когнітивного та психолінгвістичного, колоборативного та компетентнісного підходів до підготовки перекладачів.

Ключові слова: професійна підготовка перекладачів, підходи до навчання перекладу, реалізація контролю у навчанні перекладу.

Фабричная Я. Г. Киевский национальный лингвистический университет

Проблема контроля в обучении переводу: аналитический обзор подходов к профессиональной подготовке переводчиков

Аннотация. Изучая историю профессиональной подготовки переводчиков в вузах, автор статьи анализирует существующие подходы к обучению переводу с целью выделения круга вопросов, релевантных аспекту осуществления контроля как составляющей системы соответствующего обучения, с целью определения теоретических и практических проблем, требующих научного решения с учетом специфики теоретического обоснования и разработки методической системы контроля в обучении будущих филологов письменному переводу в области образования. Статья освещает основные стратегии и методы обучения переводу и предлагает аналитический обзор целей, видов и форм контроля в рамках директивного, коммуникативно-функционального, профессионально ориентированного, когнитивного и психолингвистического, колоборативного и компетентностного подходов к подготовке переводчиков. Ключевые слова: профессиональная подготовка переводчиков, подходы к обучению перевода, реализация контроля в обучении перевода.
\end{abstract}

Fabrychna Ya. Kyiv National Linguistic University

Assessment in translation teaching: analytical review of approaches to professional translators training Abstract. Introduction. The development of international cooperation in the educational domain calls for greater focus on professional translator training. In the context of internationalization of higher education, digitalization of learning and teaching environment and implementation of new forms of educational services, the issue of quality in translator preparation requires new insights into its meaning and theoretical re-thinking of the concept that concerns the assessment of the students' (philologists in translation) competence of educational texts. Grounded theorizing of the assessment system in teaching translation in the educational domain relies on the research oncommon knowledge of scientific recognition as well as the best practice suggested by the representatives of didactic approaches to professional translator training. Purpose \& Methods. Based on the analytical review of the existing theoretical approaches to professional translator training this paper makes an attempt to trace the evolution of these teaching approaches with the aim to outline the issues related to the theoretical and practical aspects of the assessment system as a key component of translation teaching which needs considering with 
the respect to the peculiarities of professional translators in the educational domain preparation. Results. The paper deals with the main strategies and methods of translation teaching and focuses on aims and forms of assessment within a teacher-centred approach and learner-centred ones such as communicative-functionalist (processcentred and profession-centred), cognitive, psycholinguistic, social constructivist, task-based and competence-based approaches to translator training. In the teacher-centred approach where it is assumed that the students learn from the "ideal" translation provided by a teacher, the aim of the assessment is to evaluate separate components of the linguistic competence. Within the process-centred and profession-centred approaches where the main goal of learning is the student autonomy, the main focus is on learning objectives, feedback on students' errors, classification of errors and the objectives of the assessment are translator's knowledge and skills while during the adoption of cognitive and psycholinguistic approaches which aim at the development of the student translators awareness of their role,the issues under consideration include assessment of abilities, self-assessment and selfcorrection. Competence-based approaches concentrate on a great variety of aspects of assessment with respect to the best achievements of other learner-centred approaches. Conclusion. Outlined aspects of assessment within the approaches analysed will serve the theoretical grounds for such issues of the development of the assessment system in teaching student philologists translation in the educational domain as aims, functions, forms, means, objectives, criteria, validity of assessment of the translator's competence.

Key words: professional translator training, approaches to translation teaching, assessment.

Постановка проблеми. Розвиток міжнародного співробітництва в галузі освіти зумовлює підвищення соціального замовлення на висококваліфікованих перекладачів, здатних виступати посередниками міжкультурного спілкування у зазначеній сфері соціально-економічного життя сучасної України. А в умовах інтернаціоналізації вищої освіти, цифрового навчання та впровадження нових форм надання освітніх послуг за допомогою нових технологій та відкритих освітніх ресурсів якісна підготовка перекладачів у галузі освіти набуває нового значення, що викликає необхідність теоретичного переосмислення концепції системи контролю сформованості у майбутніх філологів фахової компетентності у письмовому перекладі текстів освітнього дискурсу. Визначення теоретичного підгрунтя методичної системи контролю у навчанні письмового перекладу в галузі освіти потребує дослідження знань, що набули загального наукового визнання та кращих практик організації контролю у навчанні перекладу, запропонованих представниками наявних дидактичних підходів до професійної підготовки перекладачів у закладах вищої освіти.

Аналіз останніх досліджень і публікацій. Проблема фахової підготовки професійних перекладачів привертає увагу сучасних дослідників і сприяє активному пошуку шляхів оптимізації процесу навчання перекладу. 3 метою визначення теоретичних і практичних питань, що потребують наукового вирішення, науковці звертаються до історії досліджень, пов'язаних 3 певними науковими проблемами. Розгляду дидактичних концепцій навчання перекладу присвячено низку наукових розвідок. Так, зокрема описано та проаналізовано теоретичні підходи до навчання професійних перекладачів, запропоновано їх класифікацію (Kelly, 2010); розглянуто моделі навчання письмового перекладу, що засновані на засадах лінгвістичного, функціонального, психолінгвістичного та когнітивного підходів у перекладознавстві, визначено їхні переваги та недоліки з погляду методики навчання, обгрунтовано реалізацію інтегрованого, особистісно-діяльнісного та компетентнісного підходів до формування компетентності у письмовому перекладі наукових текстів (Максименко, 2017). Сутність суб' єктно-синергетичного, когнітивного та компетентнісного підходів для розроблення концепції навчання магістрів-філологів усного перекладу у зовнішньоекономічнй сфері розглянуто в науковому дослідженні Н. Зінукової (Зінукова, 2018). Історія дослідження наукової проблеми контролю сформованості перекладацької компетентності знайшла відображення у публікаціях Т. Король (Король, 2019), в яких авторка, спираючись на результати аналізу наукових джерел, розглядає можливість адаптації теоретичних аспектів реалізації контролю 
та тестування до потреб організації контролю у навчанні перекладу майбутніх філологів. Теоретичні та практичні моделі оцінювання якості перекладу проаналізовано у доробку Н. Іваницької (Іваницька, 2015). Проте нам не відомі роботи, метою яких є аналіз аспектів контролю як складової системи фахової підготовки професійних перекладачів у межах наявних підходів до навчання перекладу.

Мета статті - простежити еволюцію підходів до навчання перекладу, проаналізувати аспекти реалізації контролю як складової системи навчання з метою теоретичного обгрунтування методичної системи контролю у навчанні майбутніх філологів письмового перекладу текстів освітнього дискурсу.

Основні результати дослідження. Історія професійної підготовки перекладачів у закладах вищої освіти починається з середини XX століття як відповідь на зростання міжнародного попиту на кваліфікованих фахівців з усного та письмового перекладу. Саме тоді паралельно із початком активного розвитку перекладознавства закладаються теоретичні засади навчання перекладу, що знаходять своє відображення у різноманітності підходів до підготовки перекладачів. Орієнтуючись на загальноприйняте визначення підходу до навчання (Азимов \& Щукин, 2009), підхід до навчання перекладу розглядаємо як стратегію навчання перекладу, яка визначає вибір методів навчання, що реалізують цю стратегію; як точку зору на сутність того, як слід формувати перекладацьку компетентність. Простежимо еволюцію підходів до навчання перекладу з метою виокремлення кола питань, пов'язаних із реалізацією контролю у навчанні перекладачів.

Перші методики підготовки перекладачів з'являються у 60-70-ті роки XX століття. Вони грунтуються на лінгвістичній теорії перекладу, у центрі якої порівняльний аналіз систем мов і поняття еквівалентності між текстом оригіналу (ТО) і текстом перекладу (ТП). У цей період формується директивний підхід до навчання перекладу, спрямований на передачу знань від викладача студентам. Методи навчання, що реалізують стратегію цього підходу, передбачають самостійне виконання студентами письмового перекладу тексту; перевірку виконаного перекладу викладачем, який під час заняття запитує різні варіанти перекладу окремих речень, виправляє помилки, пропонує власний “ідеальний” варіант; виконання студентами вправ, спрямованих на вдосконалення мовних і стилістичних навичок і вмінь студентів як у вихідних, так і в цільових мовах (House \& Kiraly, 1995). Контроль здійснюється 3 боку викладача, який, орієнтуючись на власні враження, оцінює ТП за критеріями його адекватності ТО та прийнятності з точки зору цільової культури (Toury, 1995). Об'єктом контролю в межах директивного підходу, який передбачає опанування перекладацької майстерності на прикладі “ідеального” перекладу, запропонованого викладачем, виступають окремі компоненти лінгвістичної компетентності майбутніх перекладачів у рідній та іноземній мовах.

Перехід від навчання, орієнтованого на викладача, до навчання, орієнтованого на студента, відбувається з появою скопос-теорії, яка розглядає переклад як цілеспрямовану діяльність, покликану виконувати посередницьку функцію між представниками різних культур. У цей період виникає комунікативно-функціональний підхід до навчання майбутніх перекладачів, представники якого зосереджуються на методиці перекладу, розробленні навчальних матеріалів, розробленні та плануванні навчальних курсів і програм підготовки перекладачів, вдосконалення кваліфікації (Kelly, 2010). Студенти вчаться трактувати завдання в перекладі, визначати тип і вид перекладу, здійснювати інформаційний пошук, доперекладацький аналіз ТО, користуватися стратегіями перекладу, оцінювати ТП, аналізувати перекладацькі помилки (Honig \& Kußmaul, 1982). Метою навчання перекладачів в аспекті комунікативно-функціонального підходу є підготовка експертів в галузі перекладу; умовою навчання виступає автономія студента (Holz-Mänttäri, 1984), яка передбачає його залучення до визначення індивідуальних навчальних 
цілей (Sainz, 1994), самостійного вибору текстів для перекладу (House, 1977/1997) тощо. Об'єктами контролю є складові перекладацької компетентності: знання, вміння та здібності. Серед аспектів реалізації контролю в центрі уваги дослідників - такі питання: право студентів знати систему оцінювання їхніх перекладів й отримувати зворотний зв'язок (Sainz 1994); відбір текстів для поточного й підсумкового контролю (Kußmaul, 1995); визначення цілей контролю, відмінність контролю сформованості перекладацької компетентності від контролю результатів навчання, відповідність змісту та форм контролю навчальним цілям й етапам формування навичок і вмінь, вимоги до тестів, оцінювання тих, хто здійснює контроль й оцінювання (Hatim \& Mason, 1997/2005); надійність і валідність тестів (Colina, 2009). У своїх пошуках шляхів вирішення зазначених питань науковці звертаються до досліджень 3 методики навчання іноземних мов і культур.

Комунікативно-функціональний підхід знаходить практичне втілення у професійно орієнтованому підході, який грунтується на спостереженнях за процесом виконання перекладу професійними перекладачами, а методичним змістом цього підходу є спосіб організації навчальної діяльності, який максимально наближує його до умов реальної перекладацької практики (Nord, 1991). У межах професійно орієнтованого підходу порушуються питання розроблення навчальних програм, окреслюються вимоги до організації освітнього процесу, відбору навчального матеріалу за принципом від простого до складного, розроблення вправ, підвищення мотивації студентів до навчання. К. Норд пропонує критерії відбору текстів, серед яких автентичність, наявність мовних і перекладацьких труднощів, а також наголошує на необхідності класифікації перекладацьких помилок. На вибір засобів контролю впливає усвідомленість відмінностей між цілями педагогічного контролю, який спрямований на перевірку того, як студенти можуть використовувати отримані під час навчання знання, навички та вміння, або на діагностику рівня їх сформованості задля подальшого розвитку й удосконалення та кваліфікаційного тестування, яке проводиться роботодавцями з метою швидкої перевірки того, чи має перекладач необхідний набір знань, навичок і вмінь для отримання роботи. В основі системи оцінювання, запропонованої науковцем, лежить шкала накопичування балів залежно від кількості успішно виконаних завдань, рівень складності яких регулюється відповідними інструкціями.

Подальшу інтерпретацією комунікативно-функціональний підхід знаходить у спрямованих на процес перекладу когнітивному та психолінгвістичному підходах до навчання на початкових етапах підготовки перекладачів. На початку навчального курсу відбувається попередній контроль, завданням якого $є$ визначення необхідних когнітивних здібностей студентів до перекладацької діяльності, а отримані результати $є$ теоретичним підгрунтям для організації відповідного навчання. Метою навчання виступає усвідомленість ролі перекладача, аналіз помилок розглядається як потужний навчальний ресурс, а ефективність навчання залежить від здатності студентів реалізувати свій інтерлінгвальний, інтеркультурний та інтертекстуальний потенціали. До основних методів навчання відносять послідовне виконання перекладу, яке дає змогу зосередити увагу на одному аспекті та опанувати відповідну перекладацьку стратегію (Gile, 1995) та міркування вголос з метою дослідження того, що відбувається у свідомості перекладача під час перекладу (Kiraly, 1995). Фіксування студентами труднощів під час виконання перекладу та подальший аналіз помилок можна віднести до інструментів самоконтролю, самооцінювання та самокорекції.

Самоконтроль, самооцінювання, взаємоконтроль і взаємооцінювання - характерні елементи системи контролю в межах колоборативного підходу на основі соціального конструктивізму (Kiraly, 2000). Змістовим компонентом цього підходу є проєктні технології, зокрема реальний перекладацький проєкт, успішність виконання якого залежить від конструктивної взаємодії студентів між собою, з викладачем, а також з професійними перекладачами. На основі професійно 
спрямованого проєктного підходу з'являється методика, що базується на ситуаційному аналізі перекладацького завдання (Vienne, 1994; Gouadec, 2003). Навчальний процес організовується у форматі майстер-класів з реальними перекладацькими завданнями від реальних замовників, ситуаційний аналіз перекладацького завдання здійснюється під керівництвом викладача, який відповідає на запитання студентів і в такий спосіб спрямовує їх на його вирішення. Представниками цього підходу порушуються питання використання в ході реалізації контролю словників, довідників, засобів IКТ, відбору тестових матеріалів, визначення оптимальної кількості часу на виконання тесту, надійності й об'єктивності оцінювання.

Переорієнтація з процесу на результат навчання відбувається з переходом до компетентнісного підходу, передвісником якого у навчанні перекладу вважається канадський перекладознавець (Delisle, 1993). У своїй системі навчання він теоретично обгрунтовує необхідність структурувати процес підготовки перекладачів відповідно до чітко визначених навчальних цілей. Науковець доводить, що саме такий підхід сприяє кращому спілкуванню та взаємодії викладача і студентів, зумовлює вибір методів навчання, вправляння, контролю та оцінювання.

На визначенні навчальних цілей та орієнтації на навчальні результати грунтується проблемне навчання, яке знаходить відображення у розвідках Гонсалез Девісі Гуртадо (González Davies, 2005; Hurtado, 2010). Основним об’єктом уваги виступають системи вправ, спрямованих на формування й удосконалення як окремих компонентів перекладацької компетентності, так і компетентності в цілому, яка розглядається як кінцевий продукт і глобальна мета. У центрі уваги дослідників виведено процедурні та декларативні знання. В аспекті контролю акцентується розроблення контрольних і тестових завдань з урахуванням навчальних цілей. Оцінювання здійснюється з використанням системи віднімання балів відповідно до кількості і характеру помилок.

У контексті європейського простору вищої освіти, в якому компетентнісний підхід перетворився на філософію, що формує інноваційне бачення освіти, доцільною є концепція Д. Робінсона (Robinson, 2003), основною ідеєю якої є те, що підготовка професійного перекладача має складатися з академічної освіти та освіти поза межами закладу, тобто бути орієнтованою на навчання впродовж життя. Особливістю цього підходу є те, що студент і викладач у процесі навчання виступають рівними партнерами, колегами, які разом шукають шляхи вирішення певної перекладацької проблеми. В аспекті реалізації контролю автор методики наполягає на тому, що завдання для поточного контролю мають бути комунікативними та розроблені таким чином, щоб допомогти студентам отримати інформацію про те, що вони знають і вміють, тобто здійснювати самооцінку власних навчальних досягнень і розробити ефективні стратегії отримання інформації про те, чого вони не знають і не вміють. Саме через те, що результати контролю залежать від індивідуальних особливостей кожного студента і можуть відрізнятися, "правильних" або "неправильних" відповідей на завдання, на думку дослідника, не існує (Robinson, 2003).

Сучасні технології реалізації контролю у підготовці професійних перекладачів моделюються в межах компетентнісного підходу з урахуванням надбань особистісно-діяльнісних підходів до навчання перекладу. Саме вони слугують методологічним підгрунтям для вирішення таких питань: теоретичні засади визначення цілей, функцій, видів, форм, засобів, об' єктів, надійності та валідності контролю у навчанні перекладу (Waddington, 2001; Campbell, Hale, 2003; Angelelli, 2009); вимірювання рівня сформованості фахової компетентності в усному перекладі (Timarová, 2009; Ungoed-Thomas, 2009; Vermeiren та ін., 2009; Зінукова, 2018; Ольховська, 2018; Сімкова, 2018), письмовому перекладі (Кочубей, 2013; Монашенко, 2016; Король, 2020), сурдоперекладі (Bontempo, Napier, 2009); засобів контролю (Kunzli, 2009; Ігнатенко, 2017); критеріїв оцінювання якості перекладу (Jacobson, 2009; Eyckmans та ін., 2009; Tiselius, 2009; Kim, 2009; Ніколаєва, 2010; Перевьорткіна, 2010; Черноватий, 2013); розроблення інструментів оцінювання (Baer, BystrovaMcIntyre, 2009; Williams, 2013); класифікації перекладацьких помилок (Черноватий, 2013). 
Висновки і перспективи подальших розвідок. Проведений аналітичний огляд наявних теоретичних підходів до навчання професійних перекладачів у закладах вищої освіти дав змогу виокремити аспекти контролю як складової системи навчання перекладу, визначити їхню специфіку в межах кожного підходу, узагальнити основні тенденції реалізації контролю та оцінювання. Результати проведеного дослідження стануть теоретичним підгрунтям розроблення методичної системи контролю у навчанні майбутніх філологів письмового перекладу в галузі освіти.

\section{ЛIТЕРАТУРА}

Азимов, Э. Г., \& Щукин, А. Н. (2009). Новый словарь методических терминов и понятий [теория и практика обучения языкам]. Москва: ИКАР.

Максименко, Л. О. (2017). Сучасні тенденції використання дидактичних підходів у навчанні письмового перекладу. Іноземні мови, 1, 32-38.

Бігич, О. Б., Бориско, Н. Ф., Борецька Г. Е., Гапонова, С. В., Майєр, Н. В., Ніколаєва С. Ю., \& Шукліна, С. І. (2013). Методика навчання іноземних мов і культур: теорія і практика. Київ: Ленвіт.

Черноватий, Л. М. (2013). Методика викладання перекладу як спеціальності [підручник для студентів вищих закладів освіти за спеціальністю “Переклад”]. Вінниця: Нова Книга.

Angelelli, C. V. \& Jacobson, H. E. (2009). Introduction: Testing and assessment in translation and interpreting studies: A call for dialogue between research and practice. In C. V. Angelelli \& H. E. Jacobson (Eds.), Testing and Assessment in Translation and Interpreting Studies (pp. 1-12). Amsterdam \& Philadelphia: John Benjamins Publishing Company.

Colina, S. (2009). Further evidence for a functionalist approach to translation quality evaluation. Target, 21(2), 235-264.

Delisle, J. (1988). Translation: an interpretive approach (Translated by P. Logan \& M. Creery). Ottawa, Canada: University of Ottawa Press.

Gile, D. (2009). Basic Concepts and Models for Interpreter and Translator Training (Revised ed.). Amsterdam/Philadelphia: John Benjamins Publishing Company,.

González Davies, M. (2005). Minding the process, improving the product: Alternatives to traditional translator training. In M. Tennent (Ed.), Training forth a New Millennium: Pedagogies for translation and interpreting (pp. 67-82). Amsterdam/ Philadelphia: John Benjamins Publishing Company. https://doi.org/10.1075/btl.60.09gon

Gouadec, D. (2003). "Position Paper: Notes on Translator Training.” In Anthony Pym, Carmina Fallada, José Ramón Biau \& Jill Orenstein (Eds.), Innovation and E-Learning in Translator Training (pp. 11-19). Tarragona: Universitat Rovira i Virgili.

Hatim, B., \& Mason, I. (1997/2005). The translator as communicator. Taylor \& Francis e-Library.

House, J. (1977/1997/2014). Translation Quality Assessment: Past and Present. In J. House (Ed.), Translation: A Multidisciplinary Approach (pp. 241-264). New York: Palgrave Macmillan.

Hurtado Albir, A. (2010). Cognitive Approaches. In Yves Gambier \& Luc van Doorslaer (Ed.), Handbook of Translation Studies (Vol. 1, pp. 28-35). Amsterdam / Philadelphia: John Benjamins Publishing Company.

Kelly, D. (2010). Translation Didactics. In Yves Gambier \& Luc van Doorslaer (Ed.), Handbook of Translation Studies (Vol. 1, pp. 389-396). Amsterdam / Philadelphia: John Benjamins Publishing Company.

Kiraly D. A (2000). Social Constructivist Approach to Translator Education. Empowerment From Theory to Practice. Manchester, UK \& Northampton MA: St. Jerome Publishing.

Kiraly D. (1995). Pathways to Translation. Pedagogy and Process. Kent, Ohio: Kent State University Press. 
Nord, C. (1991). Text Analysis in Translation: Theory, Methodology, and Didactic Application of a Model for Translation-Oriented Text Analysis. Amsterdam \& Atlanta: Rodopi.

Robinson, D. (2003). Becoming a Translator. An Introduction to the Theory and Practice of Translation (2nd ed.). London: Routledge.

Sainz, J. M. (1992). Student-centered correction of translation. Amsterdam ; Philadelphia: John Benjamins.

Toury, G. (1995). Descriptive Translation Studies and Beyond. Amsterdam: John Benjamins.

Vienne, J. (1994). "Towards a pedagogy of 'Translation in Situation." Perspectives, 2(1), 51-59.

\section{REFERENCES}

Azimov, E. G., Schukin, A. N. (2009). Novyj slovar' metodicheskykh terminov i ponyatiy [teoriya i praktika obucheniya yazykam]. Moskva: Izdatel'stvo IKAR.

Maksymenko, L. O. (2017). Suchasni tendentsii vykorystannia dydaktychnykh pidkhodiv u navchanni pys'movoho perekladu. Inozemni movy, 1, 32-38.

Bihych, O. B., Borysko, N. F., Borets'ka H. E., Haponova, S. V., Majier, N. V., Nikolaieva S. Yu., \& Shuklina, S. I. (2013). Metodyka navchannia inozemnykh mov i kul'tur: teoriia i praktyka. Kyiv: Lenvit.

Chernovatyj, L. M. (2013). Metodyka vykladannia perekladu iak spetsial'nosti [pidruchnyk dlia studentiv vyschykh zakladiv osvity za spetsial'nistiu "Pereklad"]. Vinnytsia: Nova Knyha.

Angelelli, C. V. \& Jacobson, H. E. (2009). Introduction: Testing and assessment in translation and interpreting studies: A call for dialogue between research and practice. In C. V. Angelelli \& H. E. Jacobson (Eds.), Testing and Assessment in Translation and Interpreting Studies (pp. 1-12). Amsterdam \& Philadelphia: John Benjamins Publishing Company.

Colina, S. (2009). Further evidence for a functionalist approach to translation quality evaluation. Target, 21(2), 235-264.

Delisle, J. (1988). Translation: an interpretive approach (Translated by P. Logan \& M. Creery). Ottawa, Canada: University of Ottawa Press.

Gile, D. (2009). Basic Concepts and Models for Interpreter and Translator Training (Revised ed.). Amsterdam/Philadelphia: John Benjamins Publishing Company,.

González Davies, M. (2005). Minding the process, improving the product: Alternatives to traditional translator training. In M. Tennent (Ed.), Training forth a New Millennium: Pedagogies for translation and interpreting (pp. 67-82). Amsterdam/ Philadelphia: John Benjamins Publishing Company. https://doi.org/10.1075/btl.60.09gon

Gouadec, D. (2003). "Position Paper: Notes on Translator Training." In Anthony Pym, Carmina Fallada, José Ramón Biau \& Jill Orenstein (Eds.), Innovation and E-Learning in Translator Training (pp. 11-19). Tarragona: Universitat Rovira i Virgili.

Hatim, B., \& Mason, I. (1997/2005). The translator as communicator. Taylor \& Francis e-Library. House, J. (1977/1997/2014). Translation Quality Assessment: Past and Present. In J. House (Ed.), Translation: A Multidisciplinary Approach (pp. 241-264). New York, N. Y.: Palgrave Macmillan.

Hurtado Albir, A. (2010). Cognitive Approaches. In Yves Gambier \& Luc van Doorslaer (Ed.), Handbook of Translation Studies (Vol. 1, pp. 28-35). Amsterdam / Philadelphia: John Benjamins Publishing Company.

Kelly, D. (2010). Translation Didactics. In Yves Gambier \& Luc van Doorslaer (Ed.), Handbook of Translation Studies (Vol. 1, pp. 389-396). Amsterdam / Philadelphia: John Benjamins Publishing Company.

Kiraly D. A (2000). Social Constructivist Approach to Translator Education. Empowerment From Theory to Practice. Manchester, UK \& Northampton MA: St. Jerome Publishing. 
Kiraly D. (1995). Pathways to Translation. Pedagogy and Process. Kent, Ohio: Kent State University Press.

Nord, C. (1991). Text Analysis in Translation: Theory, Methodology, and Didactic Application of a Model for Translation-Oriented Text Analysis. Amsterdam \& Atlanta: Rodopi.

Robinson, D. (2003). Becoming a Translator. An Introduction to the Theory and Practice of Translation (2nd ed.). London: Routledge.

Sainz, J. M. (1992). Student-centered correction of translation. Amsterdam ; Philadelphia: John Benjamins.

Toury, G. (1995). Descriptive Translation Studies and Beyond. Amsterdam: John Benjamins.

Vienne, J. (1994). “Towards a pedagogy of 'Translation in Situation.” Perspectives, 2(1), 51-59. 